\author{
International Scientific Organization \\ http://iscientific.org/ \\ Chemistry International \\ www.bosaljournals.com/chemint/
}

\title{
Efficient removal of dyes in textile effluents using aluminum-based coagulant
}

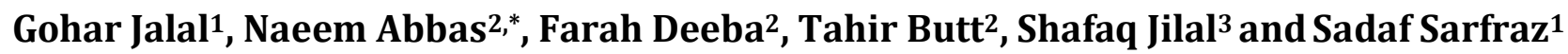 \\ ${ }^{1}$ Department of Chemistry, Lahore Garrison University, Lahore, Pakistan \\ ${ }^{2}$ Center for Environmental Protection Studies, PCSIR Laboratories Complex, Lahore, Pakistan \\ 3Department of Chemistry, Forman Cristian college University Lahore, Pakistan \\ ${ }^{*}$ Corresponding author's E. mail: naeemchemist@gmail.com
}

\section{A R T I C L E I N F O}

\section{Article type:}

Research article

Article history:

Received November 2020

Accepted April 2021

July 2021 Issue

Keywords:

Coagulation

Aluminum chloride

Textile effluents

Water quality assurance

Chemical oxygen demand

Turbidity

$\mathrm{pH}$

\section{A B S T R A C T}

The study was conducted to examine the effectiveness of aluminum-based coagulant on textile wastewater quality. Taking into account the environmental and economic factor, aluminum chloride was employed individually on wastewater as well as in combination with alum to remove the COD, turbidity and color. Four batches of $50 \mathrm{~mL}$ of wastewater were prepared then, $5 \mathrm{~mL}$ of $\mathrm{AlCl}_{3}$ and $1 \mathrm{~mL}$ alum was added in first batch named treatment T1. To optimize the treatment process for maximum reduction of COD, color and turbidity, dose of coagulants was increased by $5 \mathrm{~mL}$ of $\mathrm{AlCl}_{3}$ and $1 \mathrm{~mL}$ of alum per batch labeled with (T2, T3, T4) at original $\mathrm{pH}$ 9. Further study was conducted to evaluate the effect of $\mathrm{pH}$ on removal of color, turbidity and COD. Consequences of each treatment reveals that maximum reduction was obtained with neutral $\mathrm{pH}$ values as compared to $\mathrm{pH} 3,9$ and 11 . Treatment T3 presented remarkable results, $98 \%$ reduction in both COD and color whereas, $99 \%$ in turbidity was observed at $\mathrm{pH}$ 7. Results demonstrated the effective application of aluminum-based coagulant to treat the textile wastewater.

(c) 2021 International Scientific Organization: All rights reserved.

Capsule Summary: This study evaluates the aluminum-based coagulants for treatment of textile wastewater. The results showed that aluminum-based coagulant is efficient for color, COD and turbidity removal and improve the water quality significantly $\mathrm{pH} 7$.

Cite This Article As: G. Jalal, N. Abbas, F. Deeba, T. Butt, S. Jilal and S. Sarfraz. Efficient removal of dyes in textile effluents using aluminum-based coagulants. Chemistry International 7(3) (2021) 197-207.

https://doi.org/10.5281/zenodo.4899952

\section{INTRODUCTION}

Water has been one of the most vital renewable resources, essence of food and basic component of life. The necessity of water has been greatly ascending and has a diversified purpose in every life. It is not only vital for drinking, but also important for various developmental activities (Shishaye and Abdi, 2016). It has never been possible to substitute water with any other alternative, water transportation is very hard and expensive, (Singh and Gupta, 2016). Many areas of the world including developed countries are lacking freshwater resources for drinking and agriculture use. The water resources have been polluted due to anthropogenic activity including urbanization, industry, agriculture along with other human activities etc. Environmental agencies have been directed them to limit their industrial growth. The groundwater and surface water resources perform a significant part in hydropower generation, agriculture, livestock production, industrial activities, fisheries, navigation, forestry, recreational activities and many more (Singh and Gupta, 2016). 


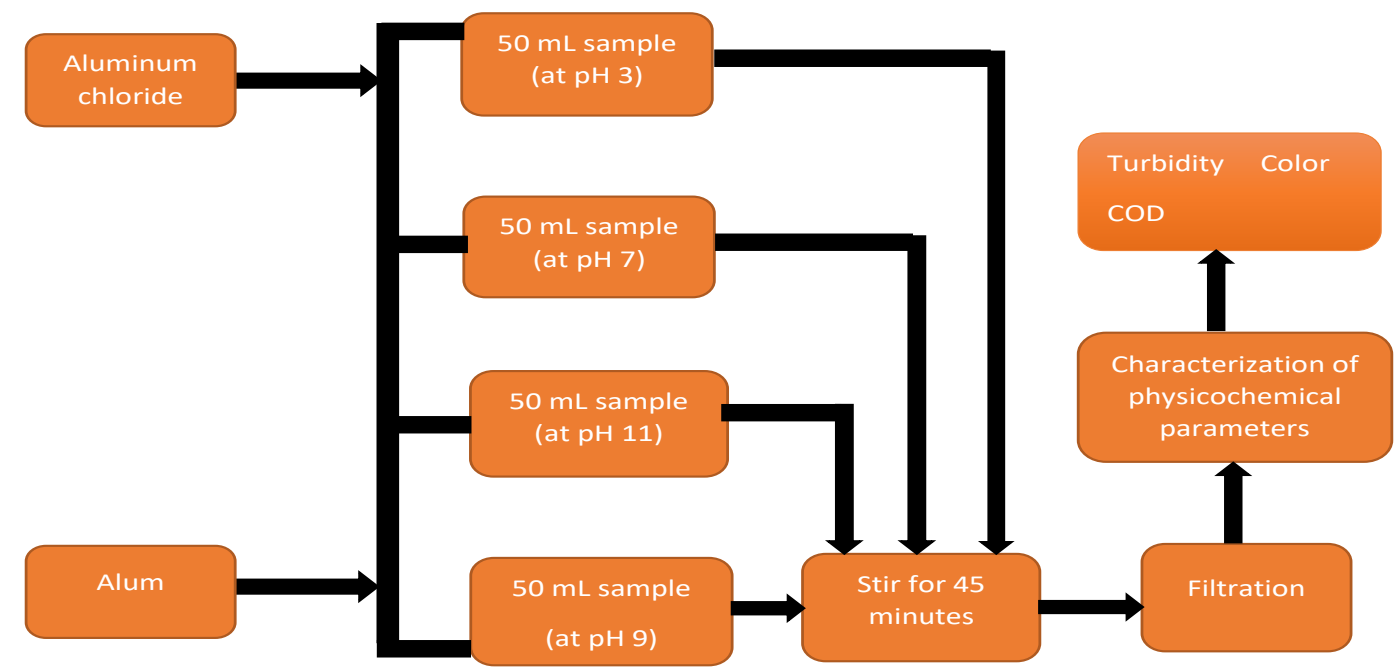

Fig. 1: Schematic protocol designed for research work

The release of wastewater from industries causing pollution not only in the rivers and ponds but chemicals are seeping down into the ground water. The exploitation of water is persisting a significant problem because of its unalloyed necessities. Groundwater has become massively significant for the diverse water source in rural and urban areas equally of both developing and developed states (Al-Garni, 2009). Amongst the entire resources of water available to the ecosystem, only $3 \%$ of the total water occurs in the form of fresh water. Rivers comprise $0.1 \%$ of the area of the land, and river channels include only $0.01 \%$ of the earth's total water. Though, the sources of the freshwater have been totally become peril which is being badly damaging the lifestyle in recent years (He and HU, 2010; Nakhate et al., 2020). Rapid industrialization is considered as one of the major aspects in generating an imbalance in the ecosystem and in the available water resources. The ecosystem has been experiencing over exploitation of the industries over the last two centuries which results in the degradation of the water quality. Usage of water and its removal has become increasingly expensive due to higher costs of fresh water used in industrial processes and its discharge as effluent (Banat and Al-Bastaki, 2004).

Among the other industries, textile industry is one of the most important and oldest industries existed since ages (Premarathne et al., 2019; Restiani, 2016). Constant and enormous supply of fresh water is required to accomplish various textile processes. Water is frequently used during dyeing and finishing procedures, containing $70-80 \%$ of the total effluents rich with dyes such as azo, vat dyes as well as organics effluents (Godin et al., 2012; Nakhate et al., 2020). Amongst all of the dyes, synthetic dyes have been frequently employed in textile industries because of their high stability, temperature and less flexibility (Wang and Chu, 2011). Centre for Science and Environment (CSE) conducted a study which reveals that approximately $200-250 \mathrm{~m}^{3}$ water has been used per ton of fabric and releases in the form of wastewater (Nakhate et al., 2020).

Wastewater bearing textile pigments have not only been displeasing the resources of water aesthetically as well as, leaving the high impacts on penetration of the light deep into water which leads to the damaging the aquatic life (Fu et al., 2011). Nearly $30 \%$ of dyes lose the binding ability and reside in dyeing tank at the end of process. Residuals of dyes in dyeing bath produce mutagenic amines, which are hazardous to environment if discharge untreated (ArslanAlaton and Alaton, 2007). It is predicted that $10-15 \%$ of the total dyes are released into the environment during various processes of the dying operations annually (Dotto et al., 2012; Owamah et al., 2013; Shertate and Thorat, 2013). Presence of dyes in wastewater has been a main concern because of their harmful effects (Rafatullah et al., 2010). The pollution generated by textile wastewater is considered as a microplastics. Microplastics are the particles of plastics lesser than $5 \mathrm{~mm}$ in size, which are derived from vast sources of manufacturing of polymer, production of clothing, processes industries and cosmetics industries etc. (Xu et al., 2018).

International cotton advisory committee 2017 reported that production of natural and synthetic fibers has reached upto100 million tons, whereas, individually synthetic fiber is considered as a plastic (Committee, 2017). Microfibers released during different processes have a capacity to absorb variety of other pollutants already present in aquatic environment and have toxic impacts on marine life such as polychlorinated biphenyl and polycyclic aromatic hydrocarbons (Keshavarzifard et al., 2015). 
Table 1: Physicochemical parameters before treatment along with NEQS standard

\begin{tabular}{llllll}
\hline Sr. & Physicochemical & Units & $\begin{array}{l}\text { Raw } \\
\text { consequences }\end{array}$ & $\begin{array}{l}\text { NEQS } \\
\text { values }\end{array}$ & Instruments used \\
\hline 1 & pH & - & 9 & $9-10$ & pH meter (JENCO 6173) \\
2 & COD & mg/L & $2,000 \pm 2.6$ & 150 & COD reactor \\
3 & Turbidity & NTU & $107 \pm 1.2$ & 4.0 & Turbidity meter (LP 2000-11) ETLl 18 \\
4 & Color & Pt-Co Hazen & $1010 \pm 3.0$ & - & Tintometer (Lovibond PFX 995) \\
5 & Conductivity & $\mu$ S/ cm & $17600 \pm 3.3$ & 3500 & Conductometer JANWAY 4010 \\
6 & TSS & mg/L & $69,000 \pm 2.0$ & 150 & Suction assembly \\
7 & TDS & mg/L & $21,666.6 \pm 3.0$ & 3500 & Drying Oven \\
\hline
\end{tabular}

Table 2: Analysis of variance for color (Pt-Co /Hazen)-Alum-AlCl 3

\begin{tabular}{lcrrr}
\hline Source of variation & DF & Sum of squares & Mean squares & F-value \\
\hline Treatment & 3 & 18018 & 6006 & $3076.02^{* *}$ \\
pH level & 4 & 8969766 & 2242442 & $1150014.00^{* *}$ \\
Treatment $x$ pH & 12 & 6407 & 534 & $273.43^{* *}$ \\
Error & 40 & 78 & 2 & \\
Total & 59 & 8994269 &
\end{tabular}

NS = Non-significant $(\mathrm{P}>0.05) ;^{*}=$ Significant $(\mathrm{P}<0.05) ;{ }^{* *}=$ Highly significant $(\mathrm{P}<0.01), \mathrm{DF}=$ Degrees of freedom

Breaking down of the bonds between microfibers which assist to degradation and decolorizing the dyes have been the utmost stage of eradicating the color and toxicity of the dye. Lots of chemical methods have been introduced such as, electro-flocculation (Pensini et al., 2019), ozonation (Li et al., 2019), oxidation (Chávez et al., 2019), electrochemical destruction (Chaplin, 2019), coagulation (Abiola, 2019), ultrafiltration (Jönsson and Wallberg, 2009; Pathiraja, 2014) for depolluting the water and save the ecosystem for living being. Effluents from industrial wastewater hold complex matrix of water and carries noxious properties which is hard to depict. Conventional methodologies, such as ultra-filtration, chemical oxidation, biological oxidation and electrochemical oxidation have been failed one way or another by the reason of infeasible efficiency, poor economy or reliability (Woisetschläger et al., 2013).

Though, numerous treatment methods consume detrimental chemicals and require extensive power for initiation and other unit operations along with production of gases, effluents and sludge (Godin et al., 2012). Apart from chemical coagulants natural coagulants are not appreciated for treatment of highly turbulent water yet can be use by the combination of natural and synthetic coagulants (Muruganandam et al., 2017). The effluents containing huge amounts of metals, salts, bases and acids are not suitable for the biological reactor because of its high-cost treatment. The combination of natural and synthetic coagulants was suggested for better result (Verma et al., 2012).

Chemical coagulation is one of the best processes reported in literature for removing the organic matters and numerous particulates (Can et al., 2019). Aluminum based salts and its alloys have been extensively used in various industries for different purposes (Junussova and Chicherin,
2020). Numerous processes have been introduced to treat industrial wastewater but the application and demand of coagulation does not diminish. Certainly, it is believed one of the most cost effective, easy to handle and simple methods. Among the various vital research, Coagulation is a popular subject for many researchers for investigating the ability of coagulation in the field of wastewater treatment. Global market of coagulant and flocculant reported that estimated use of coagulants would reach up to 6.01 billion USD by 2022 (USD 4.35 billion in 2016), the annual growth range of 5.9\% amongst 2017 and 2022 (Markets and Markets Research Private Ltd., 2017). Natural coagulants have been extensively applied on wastewater treatment, it is easily available and less challenging to handle. Researchers reveal that exclusive use of natural coagulant show less capability but combining natural coagulant with inorganic coagulant surge the efficiency of treatment (Ang and Mohammad, 2020).

Aluminum hydroxide (alum) has been one of the most common and traditional coagulant used to treat wastewater. The purpose of alum is to improve the color removal productivity and settling down the suspended solids (Mahmudov and Zuttah, 2019). Aluminum based coagulants such as aluminum chloride $\left(\mathrm{AlCl}_{3}\right)$ and alum $\mathrm{Al}_{2}\left(\mathrm{SO}_{4}\right)_{3}$ have been extensively used for coagulating the smaller particulates into bigger floc which are subsequently filtered ( $\mathrm{Hu}$ et al., 2006; Matilainen et al., 2010) . Various designs were proposed to treat wastewater through inorganic coagulants such as aluminum chloride (Genovese and González, 1998; Hu et al., 2006; Wang et al., 2019). Benschoten et al, pointed out the hydrolytic reaction of $\mathrm{Al}$ (transition metal), and the coordination bond of metal either with organic or inorganic ligands. They evaluated the interaction of both aluminum chloride and alum in aqueous solution (Mahajan et al., 2019) . 
Table 3: Interaction of mean \pm SE and reduction efficiency of color removal at various $\mathrm{pH}$ by increasing the dose

\begin{tabular}{|c|c|c|c|c|c|c|c|c|c|}
\hline \multirow{3}{*}{$\begin{array}{l}\text { Initial } \\
\mathrm{pH}\end{array}$} & \multicolumn{8}{|c|}{$1010.00 \pm 0.00 \mathrm{a}$} & \multirow{3}{*}{$\begin{array}{c}\text { Mean } \\
\text { (Initial) } \\
1010.00 \pm 0.00 \mathrm{~A}\end{array}$} \\
\hline & \multicolumn{8}{|c|}{ Treatment $+\%$ reduction efficiency } & \\
\hline & $\mathrm{T} 1$ & $\% \mathrm{R}$ & $\mathrm{T} 2$ & $\% \mathrm{R}$ & T3 & $\% \mathrm{R}$ & $\mathrm{T} 4$ & $\% \mathrm{R}$ & \\
\hline pH3 & $64.00 \pm 1.37 c$ & 93 & $46.00 \pm 0.28 \mathrm{e}$ & 94 & $28.00 \pm 0.18 \mathrm{f}$ & 97 & $22.00 \pm 0.68 \mathrm{gh}$ & 97 & $40.00 \pm 4.97 \mathrm{D}$ \\
\hline $\mathrm{pH} 7$ & $59.00 \pm 1.29 \mathrm{~d}$ & 94 & $59.00 \pm 0.89 d$ & 95 & $19.00 \pm 0.54 \mathrm{hij}$ & 98 & $15.00 \pm 0.42 j$ & 95 & $38.00 \pm 6.36 \mathrm{E}$ \\
\hline pH9 & $80.00 \pm 1.25 b$ & 92 & $80.00 \pm 1.01 b$ & 92 & $21.00 \pm 0.53 \mathrm{hi}$ & 97 & $17.00 \pm 0.43 \mathrm{ij}$ & 98 & $49.50 \pm 9.21 \mathrm{~B}$ \\
\hline pH11 & $66.00 \pm 1.84 \mathrm{c}$ & 93 & $66.00 \pm 0.61 \mathrm{c}$ & 93 & $27.00 \pm 0.87 \mathrm{f}$ & 97 & $26.00 \pm 0.28 f g$ & 97 & $46.25 \pm 5.97 \mathrm{C}$ \\
\hline Mean & \multicolumn{2}{|c|}{$255.80 \pm 100.80 \mathrm{~A}$} & $252.20 \pm 101.31 \mathrm{~B}$ & & $221.00 \pm 105.44 \mathrm{C}$ & & $218.00 \pm 105.84 \mathrm{D}$ & & \\
\hline
\end{tabular}

Table 4: Analysis of variance for COD (mg/L)-Alum-AlCl 3

\begin{tabular}{lccrr}
\hline Source of variation & DF & Sum of squares & Mean squares & F-value \\
\hline Treatment & 3 & 767325 & 255775 & $2547.46^{* *}$ \\
pH level & 4 & 29270000 & 7317953 & $72885.00^{* *}$ \\
Treatment $x$ pH & 12 & 198150 & 16512 & $164.46^{* *}$ \\
Error & 40 & 4016 & 100 & \\
Total & 59 & 30240000 & & \\
\hline
\end{tabular}

NS $=$ Non-significant $(\mathrm{P}>0.05) ;{ }^{*}=$ Significant $(\mathrm{P}<0.05) ;{ }^{* *}=$ Highly significant $(\mathrm{P}<0.01), \mathrm{DF}=$ Degrees of freedom

Table 5: Interaction of mean \pm SE and reduction efficiency of COD removal at various $\mathrm{pH}$ by increasing the dose.

\begin{tabular}{|c|c|c|c|c|c|c|c|c|c|}
\hline \multirow{3}{*}{$\frac{\text { Initial }}{\mathrm{pH}}$} & \multicolumn{8}{|c|}{$2000.00 \pm 0.00 \mathrm{a}$} & \multirow{3}{*}{$\begin{array}{c}\text { Mean } \\
\text { (Initial) } \\
2000.00 \pm 0.00 \mathrm{~A}\end{array}$} \\
\hline & \multicolumn{8}{|c|}{ Treatment $+\%$ reduction efficiency } & \\
\hline & T1 & $\% \mathrm{R}$ & $\mathrm{T} 2$ & $\% R$ & T3 & $\% R$ & $\mathrm{~T} 4$ & $\% R$ & \\
\hline pH3 & $500.00 \pm 8.82 b$ & 75 & $390.00 \pm 12.59 \mathrm{ef}$ & 80 & $210.00 \pm 2.74 \mathrm{~h}$ & 89 & $180.00 \pm 5.77 \mathrm{~h}$ & 91 & $320.00 \pm 39.76 \mathrm{~B}$ \\
\hline pH7 & $410.00 \pm 9.58 \mathrm{de}$ & 79 & $280.00 \pm 1.65 \mathrm{~g}$ & 86 & $60.00 \pm 1.15 \mathrm{kl}$ & 97 & $40.00 \pm 0.701$ & 98 & $197.50 \pm 46.68 \mathrm{E}$ \\
\hline pH9 & $430.00 \pm 6.90 \mathrm{~cd}$ & 78 & $300.00 \pm 6.08 \mathrm{~g}$ & 85 & $120.00 \pm 1.46 \mathrm{i}$ & 94 & $80.00 \pm 1.54 \mathrm{jk}$ & 96 & $232.50 \pm 42.55 \mathrm{D}$ \\
\hline pH11 & $460.00 \pm 10.35 \mathrm{c}$ & 77 & $360.00 \pm 9.39 f$ & 82 & $180.00 \pm 2.85 \mathrm{~h}$ & 91 & $110.00 \pm 1.89 \mathrm{ij}$ & 94 & $277.50 \pm 42.13 \mathrm{C}$ \\
\hline Mean & $760.00 \pm 165.93 \mathrm{~A}$ & & $666.00 \pm 178.60 \mathrm{~B}$ & & $514.00 \pm 199.05 \mathrm{C}$ & & $482.00 \pm 203.22$ & & \\
\hline
\end{tabular}

Means sharing similar letter in a row or in a column are statistically non-significant $(\mathrm{P}>0.05)$. Small letters represent comparison among interaction means and capital letters are used for overall mean.

Coagulation by metal salts has optimum method for minimizing the level of COD to the recommended limit and exhibits maximum reduction efficiency of various pollutants (Dotto et al., 2019; Huang et al., 2014). Two coagulants exhibit the potential for improving the coagulation (Zin et al., 2018). Generally, efficiency of the coagulating agents was enhanced by the operational situations such as alternation of $\mathrm{pH}$ and dose (Sun et al., 2019). However, few of the coagulating agents were discarded even at initial testing such as silver nitrate, hydrogen peroxide, anionic polymers due to their negligible effect. The study of Jiang and Graham illustratedthat aluminum based inorganic salts have been predominantly introduced for wastewater0 treatment. Aluminum ions rapidly hydrolyze, when added into wastewater in an uncontrollable way for producing a series of species of hydrolyzed metals (Jiang and Graham, 1998). A traditional coagulating agent Alum, was used to assist the coagulation process with aluminum chloride and to make the coagulation even fast (Zin et al., 2018). The investigations were made to justify the properties of alum, also used alum for removing the undesired matters from the water. Alum has been extensively used as a coagulating agent and carries significant properties (Haydar and Aziz, 2009; Nkalane et al., 2019; Omoike, 1999). Prakash et al, also significantly reported the extensive use of alum as a coagulating agent because of its relatively low price and simpler pathway of application (Prakash et al., 2014).

The study of the Prakash and his coworkers reported that Alum has been best agent for removing the color around $76 \%$ whereas $80 \%$ of the turbidity at $\mathrm{pH} 7$. They concluded that optimum concentration of Alum is $120 \mathrm{mg} / \mathrm{L}$ and it has 98.9\% removal efficiency under specific conditions (Prakash et al., 2014). 
Table 6: Analysis of variance for turbidity (mg/L)-Alum- $\mathrm{AlCl}_{3}$

\begin{tabular}{lccrr}
\hline Source of variation & DF & Sum of squares & Mean squares & F-value \\
\hline Treatment & 3 & 4861.4 & 1620.5 & $5115.15^{* *}$ \\
pH level & 4 & 83908.5 & 20977.1 & $66216.80^{* *}$ \\
Treatment $x \mathrm{pH}$ & 12 & 1255.6 & 104.6 & $330.30^{* *}$ \\
Error & 40 & 12.7 & 0.3 & \\
Total & 59 & 90038.2 & & \\
\hline
\end{tabular}

NS $=$ Non-significant $(\mathrm{P}>0.05) ;{ }^{*}=$ Significant $(\mathrm{P}<0.05) ;{ }^{* *}=$ Highly significant $(\mathrm{P}<0.01), \mathrm{DF}=$ Degrees of freedom

Table 7: Interaction mean \pm SE and reduction efficiency of turbidity at various $\mathrm{pH}$

\begin{tabular}{|c|c|c|c|c|c|c|c|c|c|}
\hline \multirow{3}{*}{$\begin{array}{l}\text { Initial } \\
\mathrm{pH}\end{array}$} & \multicolumn{8}{|c|}{$107.00 \pm 0.00 \mathrm{a}$} & Iean \\
\hline & & & Treatment & $+\% \mathrm{re}$ & iction efficiency & & & & (Initial) \\
\hline & $\mathrm{T} 1$ & $\% \mathrm{R}$ & $\mathrm{T} 2$ & $\% \mathrm{R}$ & $\mathrm{T} 3$ & $\% \mathrm{R}$ & T4 & $\% \mathrm{R}$ & $107.00 \pm 0.00 \mathrm{~A}$ \\
\hline pH3 & $33.00 \pm 0.56 b$ & 69 & $22.40 \pm 0.36 \mathrm{~d}$ & 79 & $4.87 \pm 0.07 \mathrm{f}$ & 95 & $4.70 \pm 0.09 \mathrm{fg}$ & 95 & $16.24 \pm 3.64 \mathrm{~B}$ \\
\hline $\mathrm{pH} 7$ & $24.00 \pm 0.51 d$ & 77 & $19.60 \pm 0.56 \mathrm{e}$ & 83 & $0.80 \pm 0.02 \mathrm{i}$ & 99 & $1.00 \pm 0.02 \mathrm{i}$ & 99 & $11.35 \pm 3.19 \mathrm{E}$ \\
\hline $\mathrm{pH} 9$ & $27.00 \pm 0.37 \mathrm{c}$ & 74 & $20.20 \pm 0.41 \mathrm{e}$ & 81 & $2.20 \pm 0.03 \mathrm{hi}$ & 97 & $1.20 \pm 0.04 \mathrm{i}$ & 98 & $12.65 \pm 3.38 \mathrm{D}$ \\
\hline pH11 & $28.00 \pm 0.53 c$ & 73 & $22.50 \pm 0.71 d$ & 79 & $3.10 \pm 0.08 \mathrm{gh}$ & 97 & $3.00 \pm 0.02 \mathrm{gh}$ & 97 & $14.15 \pm 3.40 \mathrm{C}$ \\
\hline Mean & $43.80 \pm 8.48 \mathrm{~A}$ & & $38.34 \pm 9.18 \mathrm{~B}$ & & $23.59 \pm 11.15 \mathrm{C}$ & & $23.38 \pm 11.18 \mathrm{C}$ & & \\
\hline
\end{tabular}

Means sharing similar letter in a row or in a column are statistically non-significant $(\mathrm{P}>0.05)$. Small letters represent comparison among interaction means and capital letters are used for overall mean.

The process of coagulation was carried out with subsequent objectives. To compare the effectiveness of optimize $\mathrm{pH}$ of coagulating agents used in terms of \%age reduction of COD, turbidity and color of the effluent. To analyze the optimum dosing rate for coagulant agent at different $\mathrm{pH}$ for maximum reduction in COD, turbidity and color. To indicate the superiority of aluminum-based coagulation in relation to cost, time and dosage over other processes.

\section{MATERIAL AND METHODS}

\section{Sampling}

Sample of textile wastewater was collected from M/s Hafiz textile and dying industry Gujranwala. The wastewater was transported into the laboratory and samples were preserved according to the standard methods for further analysis of color, COD, TDS, TSS, conductivity, turbidity and odour (APHA. 1992). All the chemicals used in research were of analytical grade. $\mathrm{pH}$ of the wastewater sample was measured at site with pH meter.

\section{Physicochemical analysis of textile wastewater}

For the purpose of estimating the efficiency of the treated wastewater by using different coagulating and flocculating agents, raw samples were examined through parameters like color, chemical oxygen demand (COD), turbidity, (TSS), total dissolved solids (TDS), $\mathrm{pH}$ and electrical conductivity by using standard methods for examination of water and wastewater (APHA 2017). A huge amount of suspended and dissolved solids in the water flow increases the chemical oxygen demand and biological oxygen demand. Likewise, TDS and TSS reduce the level of oxygen in the water system (Zhou et al., 2019). Analysis of physicochemical parameters are described in detail below in Table 1.

\section{Experimental scheme}

The raw sample was characterized typically by evaluating the COD, TSS, TDS, color, turbidity and other metals. Though, eliminating the color, lowering down the COD and turbidity have been challenging (Lau and Ismail, 2009). The major chemicals used in research work was aluminum chloride $\left(\mathrm{AlCl}_{3}\right)$ and Alum $\left[\mathrm{Al}_{2}\left(\mathrm{SO}_{4}\right)_{3} \cdot \mathrm{nH}_{2} \mathrm{O}\right]$. A 5\% stock solution of each coagulant was prepared. The following research was run by varying the dose of coagulant by keeping the volume of sample constant. To optimize removal efficiency, $\mathrm{pH}$ of the sample was altered with different concentration of alum-based coagulants. The calculated amount of the coagulants was added into the wastewater to check out the efficiency.

In this research, $50 \mathrm{~mL}$ of the wastewater was taken while, the concentration of coagulants was increased from 5 $\mathrm{mL}$ to $20 \mathrm{~mL}$. pH meter (JENCO 6173) was used for measuring the $\mathrm{pH}$ of the samples, which was adjusted by using sodium hydroxide and sulphuric acid. The prepared sample was vigorously stirred for $15 \mathrm{~min}$ at $150 \mathrm{rpm}$, which subsequently stirred at $50 \mathrm{rpm}$ for $30 \mathrm{~min}$. Thereafter the treated sample was left to settle down for sedimentation for next 30 minutes (Irfan et al., 2017). The designed protocol of research work is shown in Figure 1. 


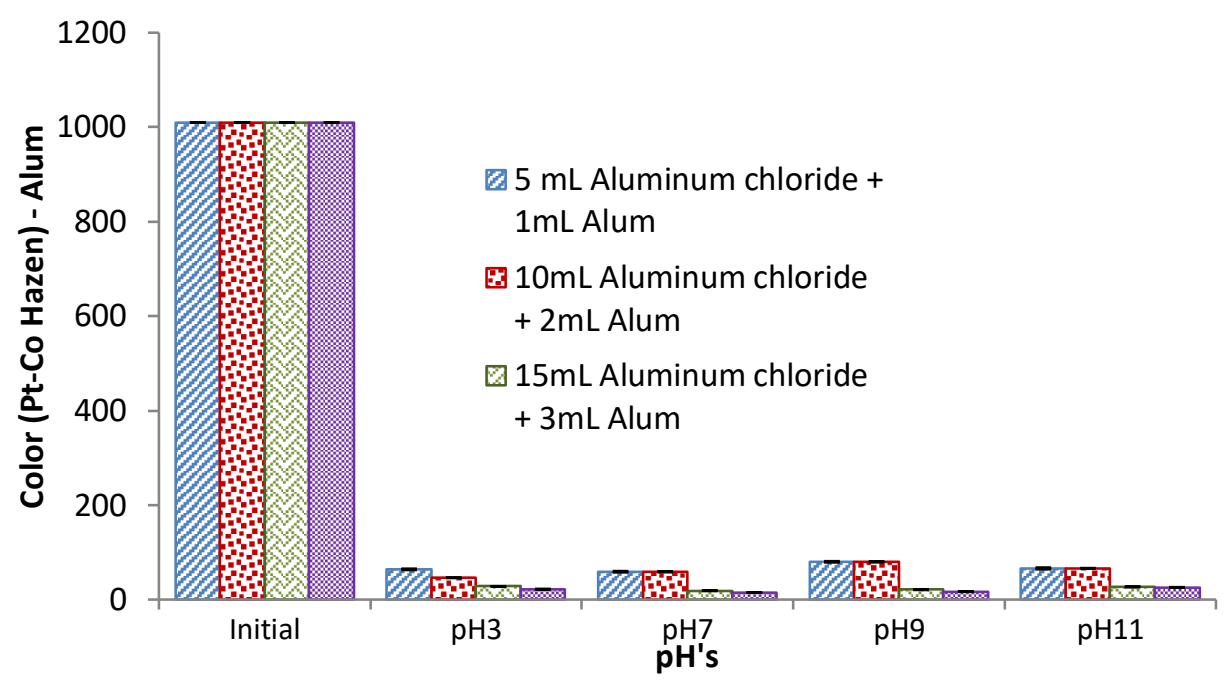

Fig. 2: Color reduction at varying $\mathrm{pH}$ by increasing the dose

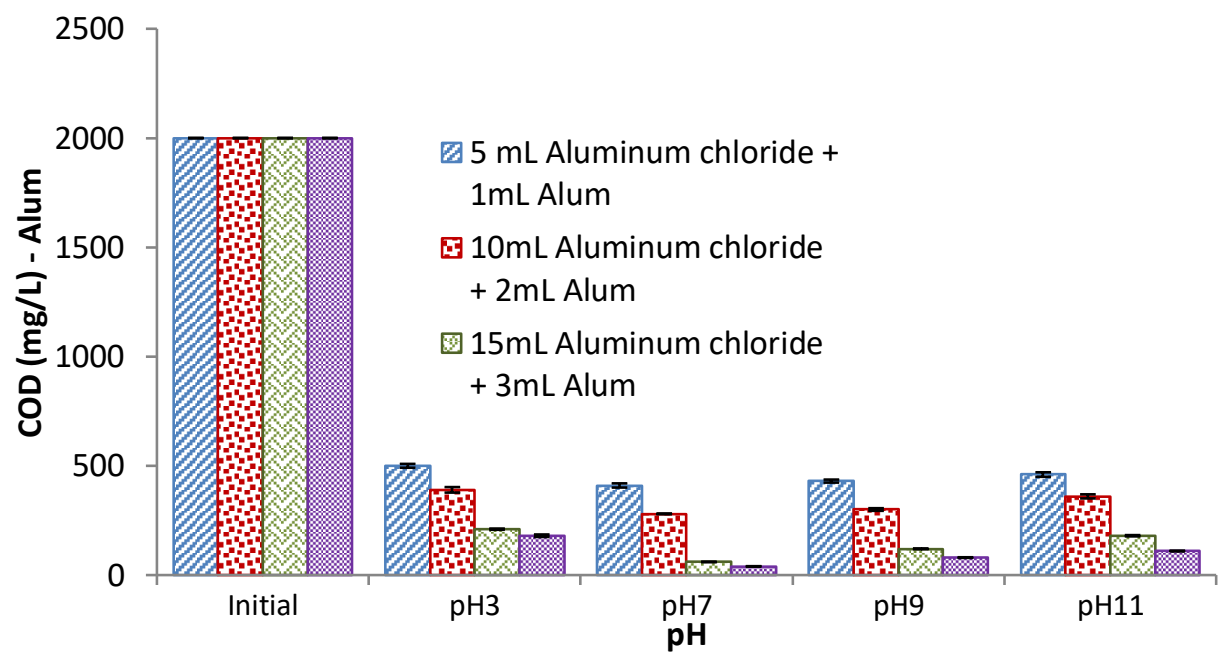

Fig. 3: COD reduction at varying $\mathrm{pH}$ by increasing the dose

\section{Analytical procedure}

Coagulation is believed to be a best process for removing the organic matters and numerous particulates using Alum and aluminum-based salts (Irfan et al., 2017). Dose of coagulant, nature of wastewater, temperature, $\mathrm{pH}$ and many other factors influence the performance of treatment. Various experiments were conducted to analyze the influence of concentration of dose and $\mathrm{pH}$ on the reduction capability of coagulants (Zin et al., 2018). By keeping the volume of the sample constant $(50 \mathrm{~mL})$ concentration of the $5 \%$ aluminum chloride and $5 \%$ alum were altered $(5,10,15$ and 20$)$ and $(1$, 2, 3 and 4) respectively. Dose of $5 \mathrm{~mL}$ of aluminum chloride was taken with the combination of $1 \mathrm{~mL}$ of alum which represented as treatment $\mathrm{T} 1$, similarly, following doses $(10$, $15,20 \mathrm{~mL})$ of aluminum chloride with $(2,3,4 \mathrm{~mL})$ of alum represented as treatment $\mathrm{T} 2$, treatment $\mathrm{T} 3$, treatment $\mathrm{T} 4$ respectively. All the treatments were conducted twice, to check the reliability of results. The experimental error was found below $2 \%$, and average data have reported (Can et al., 2019).

\section{RESULTS AND DISCUSSION}

The physicochemical parameters of wastewater were studied in terms of total dissolved solids (TDS), turbidity, color, chemical oxygen demand (COD), conductivity, $\mathrm{pH}$, total suspended solids (TSS) The influence of such parameters strongly varies in different textile wastewater due to the rate of load of organic and inorganic matters in the wastewater (Abiola, 2019). 


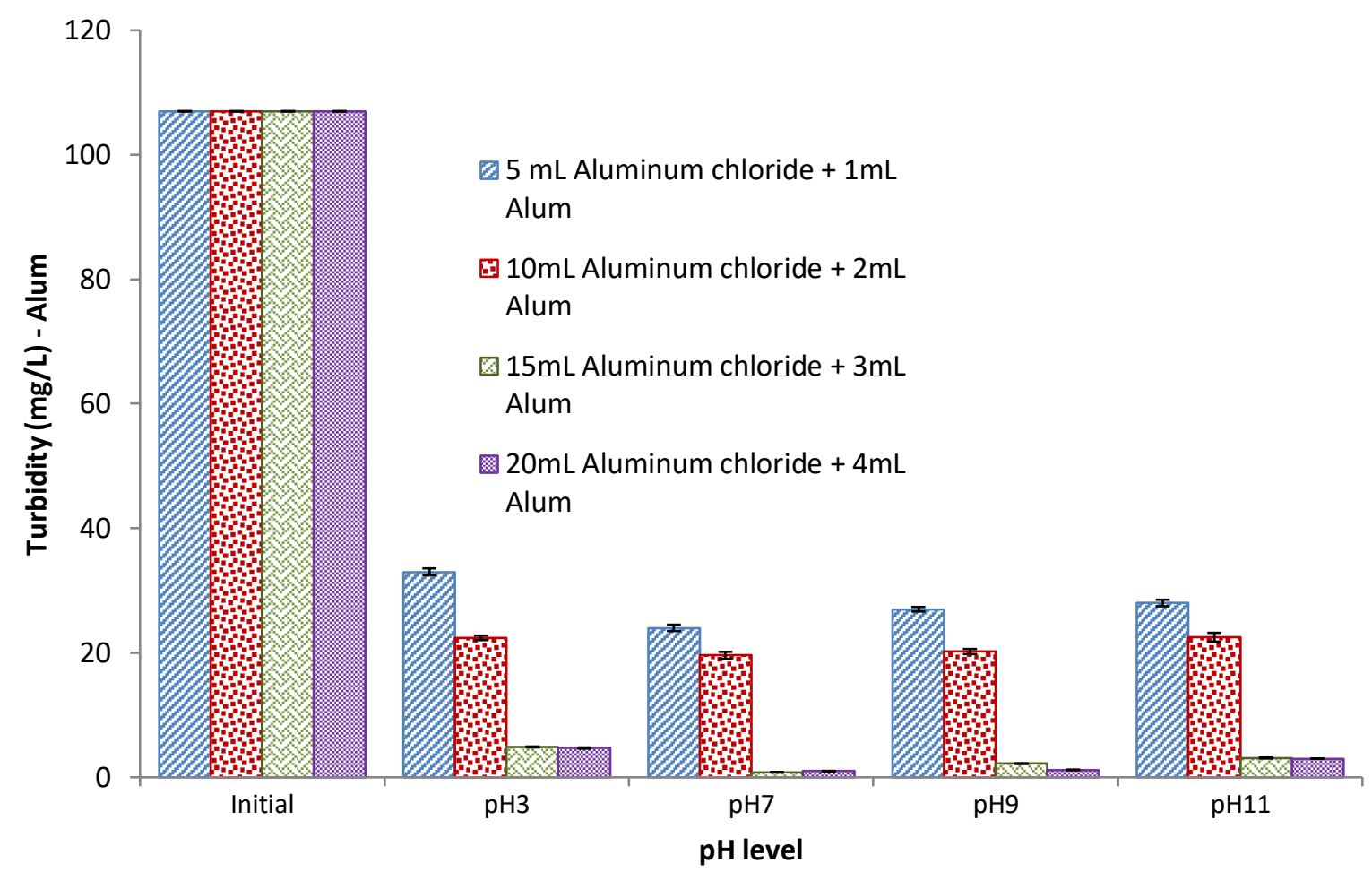

Fig. 4: Turbidity reduction at varying $\mathrm{pH}$ by increasing the dose

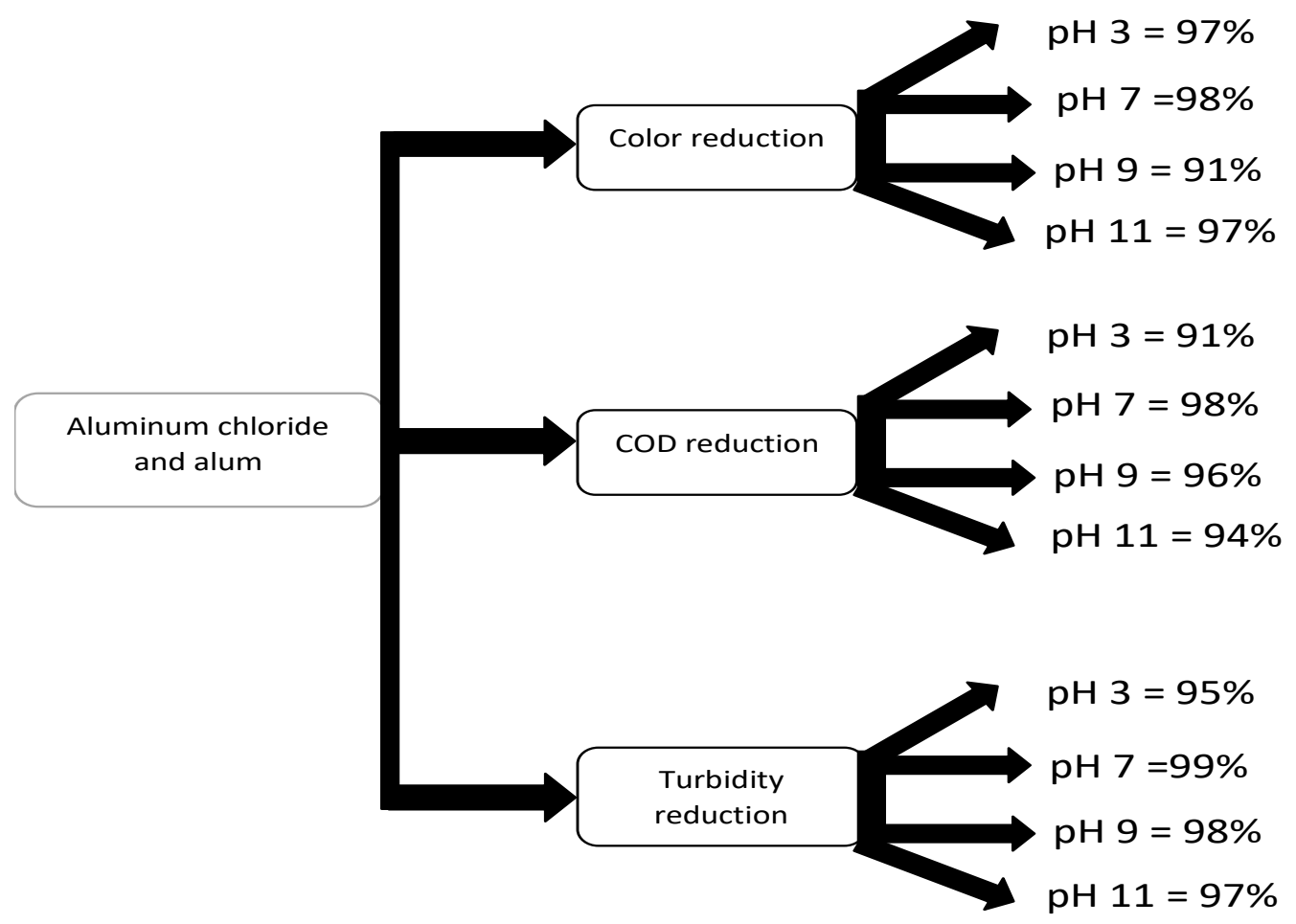

Fig. 5: Percentage reduction of all parameters with treatment $\mathrm{T} 5$ at different $\mathrm{pH}$ 
Following parameters such as COD $(2,000 \pm 2.6 \mathrm{mg} / \mathrm{L})$, TDS $(21,666.6 \pm 3.0 \mathrm{mg} / \mathrm{L})$, TSS $(69,000 \pm 2.0 \mathrm{mg} / \mathrm{L})$, color $(1010 \pm 3.0 \mathrm{mg} / \mathrm{L})$, turbidity $(107 \pm 1.2 \mathrm{NTU}) \mathrm{pH}$ (9) and conductivity $(17600 \pm 3.3 \mu \mathrm{S} / \mathrm{cm})$ were remarkably higher than NEQS standards shown in Table 1 (Ho et al., 2020). Results and observation of the coagulant are shown in Tables (2-8) and Figures (2-4).

\section{Color reduction}

Color of unprocessed textile wastewater was typically found 1010 Pt-Co Hazen. The following research work illustrated that $98 \%$ of the color removal was done successfully. It was observed that up to $94 \%$ of color removal was analyzed at treatment $\mathrm{T} 1$ ( $5 \mathrm{~mL} \mathrm{AlCl}_{3}$ and $2 \mathrm{~mL}$ alum), similarly, $95 \%$ and $98 \%$ reduction is observed with $\mathrm{T} 2\left(10 \mathrm{~mL} \mathrm{AlCl}_{3}\right.$ and $2 \mathrm{~mL}$ alum) and $\mathrm{T} 3$ (15 $\mathrm{mL} \mathrm{AlCl} 3$ and $2 \mathrm{~mL}$ alum) respectively. whereas, $98 \%$ of results were noticed with treatment $\mathrm{T} 4$ (20 $\mathrm{mL} \mathrm{AlCl}_{3}$ and $4 \mathrm{~mL}$ alum), it was observed that further increase in dose showed less significant results because the binding color pigment was reached to optimum dosage. This is because the color particles start to re-stabilizing them through excessive use of alum hydrolysis species (Wong et al., 2007). Whereas, maximum result was found with $\mathrm{pH} 7$ at treatment $\mathrm{T} 3$. The $\mathrm{pH}$ indicted practically significant result in treating color removal present in wastewater, meanwhile acidic conditions my lead to discharge of acidic wastewater since, percentage of color removal at acidic conditions are less significant as compare to neutral $\mathrm{pH}$. The efficiency of color removal with acidic and alkaline solution moderately effected, however, $\mathrm{pH} 3$ and 9 made nearly equal result in between of acidic and basic medium (Mohamed et al., 2014). Liu et al, conducted an experiment to exhibit the impact of Al-based coagulants (Liu et al., 2019). Color removing efficiency was gradually improved with increasing the dose of the coagulating agents as shown in Figure 2. The ANOVA analysis for color indication with treatment of aluminum chloride and alum have been significant as shown in Table 2. Means of various treatments were compared which proved treatment $\mathrm{T} 1$ at $\mathrm{pH} 3,7,9,11$ along with treatment $\mathrm{T} 2$ at $\mathrm{pH}$ 7, 9, 11 and treatment $\mathrm{T} 3$ at $\mathrm{pH} \mathrm{3,11}$ statistically nonsignificant. However, rest of the treatments were statistically significant as shown in Table 3.

\section{COD reduction}

Chemical oxygen demand (COD) has been one of the extensively used parameters for analysis of wastewater, it has been the indicator for identifying the effluents which are organic matters. The reporting results of the analysis must give approximate quantitative indication of uncertainty. (Drolc et al., 2003). The effect of $\mathrm{pH}$ and dose of coagulant on the removal of COD from textile wastewater is shown below. Among all the different pH's, pH 7 (neutral) was observed as optimum $\mathrm{pH}$ for lowering the COD from textile wastewater. Surprisingly reduction of COD observed nearly equal at acidic and basic $\mathrm{pH}$. Production of $\mathrm{OH}^{-}$or rerelease of dioxide gas lowers down the level of COD. COD reduction enhanced progressively by increasing the concertation of the coagulating agents as shown in Figure 3. Maximum percentage of COD removal is observed with $\mathrm{T} 3(15 \mathrm{~mL} \mathrm{AlCl} 3$ and $3 \mathrm{~mL}$ alum) and amount of COD was slightly increased with $\mathrm{T} 4(20 \mathrm{~mL} \mathrm{AlCl} 3$ and $4 \mathrm{~mL}$ alum $)$ because coagulant reduces efficiency since reach at optimum condition. Excessive use of chemical dose resulted in surging the level of COD, since T4 showed dropping of percentage of COD removal (Hua et al., 2019). The study of Piotr Marcinowski et al, proclaimed that inorganic coagulants such as aluminum chloride and alum have been significantly suitable for decreasing the level of COD in wastewater (Marcinowski et al., 2019). The ANOVA analysis of COD with different doses were significant as presented in Table 4 . Means of various treatments were compared which proved $\mathrm{T} 2$ at $\mathrm{pH} 7,9$ along with treatment $\mathrm{T} 3$ at $\mathrm{pH} \mathrm{3}$, and treatment $\mathrm{T} 4$ at $\mathrm{pH} 3$ statistically non-significant. However, rest of the treatments were statistically significant as shown in Table 5.

\section{Turbidity}

Aluminum chloride and alum together were able to remove the turbidity from wastewater with efficiency rate of up to $77 \%, 82 \%, 99 \%$ and $99 \%$ at treatment $\mathrm{T} 1$ ( $5 \mathrm{~mL} \mathrm{AlCl}_{3}$ and 1 $\mathrm{mL}$ alum), treatment $\mathrm{T} 2(10 \mathrm{~mL} \mathrm{AlCl} 3$ and $2 \mathrm{~mL}$ alum), treatment $\mathrm{T} 3\left(15 \mathrm{~mL} \mathrm{AlCl}_{3}\right.$ and $3 \mathrm{~mL}$ alum) and treatment $\mathrm{T} 4$ (20 $\mathrm{mL} \mathrm{AlCl}_{3}$ and $4 \mathrm{~mL}$ alum), respectively. At alkaline and acidic $\mathrm{pH}$, decrease in removal of turbidity happens because of production of excessive $\mathrm{OH}^{-}$production and significant sludge is also produced (Dotto et al., 2019). The working efficiency of coagulants at acidic $\mathrm{pH}$ was less so far, acidic medium increases the production of sludge somehow, which is why slightly better percentage found out with neutral $\mathrm{pH}$. The study of Paul et al., demonstrated the potency of metal coagulants like as alum and aluminum chloride and reported the reduction in turbidity from wastewater (Chadik and Amy, 1983; Mazloomi et al., 2019) . The maximum removal of turbidity was found at $\mathrm{pH} 7$ in case of treatment $\mathrm{T} 3$ and treatment $\mathrm{T} 4$ whereas, minimum reduction in turbidity was obtained at acidic $\mathrm{pH}$. The results of treatment revealed that removal in turbidity was increased with the increase in dosage of coagulating agents (Nkalane et al., 2019). The linear reduction efficiency was observed with each of treatment, suchlike by the increase in concentration of the coagulants the rate of \% age reduction was increasing as sown in Figure 4. The ANOVA table for the analysis of turbidity with different doses were significant as presented in Table 4. Means of various treatments were compared which proved treatment $\mathrm{T} 1$ at $\mathrm{pH} 7,9,11$ along with treatment $\mathrm{T} 2$ at $\mathrm{pH} 3,7,9,11$ and treatment $\mathrm{T} 3$ at $\mathrm{pH}$ 7, 11 and treatment $\mathrm{T} 4$ at $\mathrm{pH} 7,9,11$ statistically non-significant. However, rest of the treatments were statistically significant as shown in Tables 6-7. Coagulation has been renowned process for wastewater treatment. Aluminum based salts are most commonly applied such as aluminum chloride and alum (Kristianto et al., 2019). It has been extensively known 
that application of metal coagulants causes serious drawbacks. The study of Michael J. and coworkers reported that alum was found out to be significant coagulant and the removal with such coagulant was dependent on concentration of coagulant and $\mathrm{pH}$ (Semmens and Field, 1980). The effect of coagulating agents on removal of color, COD and turbidity was studied/checked with treatment T2, treatment T3, treatment T4 and treatment T5. Each of the treatment was further investigated by varying the $\mathrm{pH}$ of sample (Jin et al., 2018).

\section{CONCLUSIONS}

Coagulation process was successfully implemented to treat textile wastewater. This study investigated that, aluminumbased salts such as aluminum chloride and alum were proved best combination for treating wastewater. Concentration of both coagulants were increased successively to find out the maximum reduction. In addition to that $\mathrm{pH}$ of the wastewater was altered to acidic and basic as well. Statistical data demonstrated that $\mathrm{pH}$ 6.5-7.5 found out to be an appropriate medium for maximum reduction of COD, color and turbidity. Treatment $\mathrm{T} 5$ reduced coloring content to $98 \%$ at $\mathrm{pH} 7$, likewise $98 \%$ and 99\% reduction in COD and turbidity were examined respectively. The investigation was made that $\mathrm{pH} 3$ was least efficient $\mathrm{pH}$ for treating the wastewater for instance COD reduced to $98 \%$ with $\mathrm{pH} 7$ whereas, $91 \%$ reduction was noticed at $\mathrm{pH} 3$, same trend was observed for color and turbidity. Treatment $\mathrm{T} 4$ results were quite closer to $\mathrm{T} 5$, and it was observed that linear increase in reduction was happened with the increase in dose of coagulants. Though alum leaves high level of aluminum in treated water at low $\mathrm{pH}$, so, making that view in consideration minimum amount of alum was added.

\section{REFERENCES}

Abiola, O.N., 2019. Polymers for coagulation and flocculation in water treatment, Polymeric Materials for Clean Water. Springer, pp. 77-92.

Al-Garni, M.A., 2009. Geophysical investigations for groundwater in a complex subsurface terrain, Wadi Fatima, KSA: A case history. Jordan Journal of Civil Engineering 3, 118-136.

Ang, W.L., Mohammad, A.W., 2020. State of the art and sustainability of natural coagulants in water and wastewater treatment. Journal of Cleaner Production 262, 121267.

Arslan-Alaton, I., Alaton, I., 2007. Degradation of xenobiotics originating from the textile preparation, dyeing, and finishing industry using ozonation and advanced oxidation. Ecotoxicology and Environmental Safety 68, 98-107.

Banat, F., Al-Bastaki, N., 2004. Treating dye wastewater by an integrated process of adsorption using activated carbon and ultrafiltration. Desalination 170, 69-75.
Can, O.T., Gengec, E., Kobya, M., 2019. TOC and COD removal from instant coffee and coffee products production wastewater by chemical coagulation assisted electrooxidation. Journal of Water Process Engineering 28, 28-35.

Chadik, P.A., Amy, G.L., 1983. Removing trihalomethane precursors from various natural waters by metal coagulants. Journal-American Water Works Association 75, 532-536.

Chaplin, B.P., 2019. The Prospect of Electrochemical Technologies Advancing Worldwide Water Treatment. Accounts of Chemical Research 52, 596-604.

Chávez, A., Gimeno, O., Rey, A., Pliego, G., Oropesa, A., Álvarez, P., Beltrán, F., 2019. Treatment of highly polluted industrial wastewater by means of sequential aerobic biological oxidation-ozone based AOPs. Chemical Engineering Journal 361, 89-98.

Committee, I.C.A., 2017. World Textile Demand Report: World Consumption of Major Textile Fibers. International Cotton Advisory Committee, Washington, DC, USA.

Dotto, G.L., Vieira, M.L., Pinto, L.A., 2012. Kinetics and mechanism of tartrazine adsorption onto chitin and chitosan. Industrial \& Engineering Chemistry Research 51, 6862-6868.

Dotto, J., Fagundes-Klen, M.R., Veit, M.T., Palácio, S.M., Bergamasco, R., 2019. Performance of different coagulants in the coagulation/flocculation process of textile wastewater. Journal of Cleaner Production 208, 656-665.

Drolc, A., Cotman, M., Roš, M., 2003. Uncertainty of chemical oxygen demand determination in wastewater samples. Accreditation and Quality Assurance 8, 138-145.

Fu, F., Gao, Z., Gao, L., Li, D., 2011. Effective adsorption of anionic dye, alizarin red $\mathrm{S}$, from aqueous solutions on activated clay modified by iron oxide. Industrial \& Engineering Chemistry Research 50, 9712-9717.

Genovese, C.V., González, J.F., 1998. Solids removal by coagulation from fisheries waste waters. Water SA 24, 371-372.

Godin, D., Bouchard, C., Vanrolleghem, P., 2012. Net environmental benefit: introducing a new LCA approach on wastewater treatment systems. Water Science and Technology 65, 1624-1631.

Haydar, S., Aziz, J.A., 2009. Characterization and treatability studies of tannery wastewater using chemically enhanced primary treatment (CEPT) - a case study of Saddiq Leather Works. Journal of Hazardous Materials 163, 10761083.

He, C., HU, X., 2010. A novel functionalized ordered mesoporous carbon as an effective adsorbent for dye removal from water. http://hdl.handle.net/1783.1/7014.

Ho, Y.-C., Chua, S.-C., Chong, F.-K., 2020. Coagulationflocculation technology in water and wastewater treatment, handbook of research on resource management for pollution and waste treatment. IGI Global, pp. 432-457. 
Hu, C., Liu, H., Qu, J., Wang, D., Ru, J., 2006. Coagulation behavior of aluminum salts in eutrophic water: significance of Al13 species and $\mathrm{pH}$ control. Environmental Science and Technology 40, 325-331.

Hua, T.H., Affam, A.C., Chung, W.C., Swee, W.C., Adebayo, J.O., 2019. Activation of persulphate by heat, $\mathrm{pH}$, and transition metals for removal of COD and colour from biologically treated palm oil mill effluent, AIP Conference Proceedings. AIP Publishing LLC, pp. 020007.

Huang, X., Bo, X., Zhao, Y., Gao, B., Wang, Y., Sun, S., Yue, Q., Li, Q., 2014. Effects of compound bioflocculant on coagulation performance and floc properties for dye removal. Bioresource Technology 165, 116-121.

Irfan, M., Butt, T., Imtiaz, N., Abbas, N., Khan, R.A., Shafique, A., 2017. The removal of COD, TSS and colour of black liquor by coagulation-flocculation process at optimized $\mathrm{pH}$, settling and dosing rate. Arabian Journal of Chemistry 10, S2307-S2318.

Jiang, J.-Q., Graham, N.J., 1998. Pre-polymerised inorganic coagulants and phosphorus removal by coagulation-a review. Water SA 24, 237-244.

Jin, P., Song, J., Yang, L., Jin, X., Wang, X.C., 2018. Selective binding behavior of humic acid removal by aluminum coagulation. Environmental Pollution 233, 290-298.

Jönsson, A.-S., Wallberg, 0., 2009. Cost estimates of kraft lignin recovery by ultrafiltration. Desalination 237, 254-267.

Junussova, L., Chicherin, S., 2020. Wastewater treatment and application in the advanced nanofiltration system, IOP Conference Series: Earth and Environmental Science. IOP Publishing, pp. 012024.

Keshavarzifard, M., Zakaria, M.P., Hwai, T.S., Yusuff, F.M., Mustafa, S., 2015. Distributions and source apportionment of sediment-associated polycyclic aromatic hydrocarbons (PAHs) and hopanes in rivers and estuaries of Peninsular Malaysia. Environmental Science and Pollution Research 22, 9424-9437.

Kristianto, H., Rahman, H., Prasetyo, S., Sugih, A.K., 2019. Removal of Congo red aqueous solution using Leucaena leucocephala seed's extract as natural coagulant. Applied Water Science 9, 88.

Lau, W.-J., Ismail, A., 2009. Polymeric nanofiltration membranes for textile dye wastewater treatment: preparation, performance evaluation, transport modelling, and fouling control-a review. Desalination 245, 321-348.

Li, K., Xu, L., Zhang, Y., Cao, A., Wang, Y., Huang, H., Wang, J., 2019. A novel electro-catalytic membrane contactor for improving the efficiency of ozone on wastewater treatment. Applied Catalysis B: Environmental 249, 316321.

Liu, Z., Zhou, L., Liu, F., Gao, M., Wang, J., Zhang, A., Liu, Y., 2019. Impact of Al-based coagulants on the formation of aerobic granules: Comparison between poly aluminum chloride (PAC) and aluminum sulfate (AS). Science of the Total Environment 685, 74-84.

Mahajan, A., Nadi, R.R., Pai, V.S., Joshi, S., 2019. Comparative evaluation of experimental chitosan gingival retraction cords with aluminum chloride and nonimpregnated retraction cords: An In vivo study. Journal of Interdisciplinary Dentistry $9,1$.

Mahmudov, R., Zuttah, S., 2019. Aluminum hydroxide coagulant recovery from water/wastewater treatment sludge. U.S. Patent No. 10,358,355. Washington, DC: U.S. Patent and Trademark Office.

Marcinowski, P., Bogacki, J., Majewski, M., Zawadzki, J., Sivakumar, S., 2019. Application of aluminum-based coagulants for improving efficiency of flue gas desulfurization wastewater treatment in coal-fired power plant, E3S Web of Conferences. EDP Sciences, pp. 02006.

Matilainen, A., Vepsäläinen, M., Sillanpää, M., 2010. Natural organic matter removal by coagulation during drinking water treatment: a review. Advances in Colloid and Interface Science 159, 189-197.

Mazloomi, S., Zarei, A., Nourmoradi, H., Ghodsei, S., Amraei, P., Haghighat, G.A., 2019. Optimization of coagulationflocculation process for turbidity removal using response surface methodology: a study in Ilam water treatment plant, Iran. Desalination and Water Treatment 147, 234242.

Mohamed, R., Saphira, R.M., Kutty, A.I., Mariam, N., Kassim, M., Hashim, A., 2014. Efficiency of using commercial and natural coagulants in treating car wash wastewater treatment. Australian Journal of Basic and Applied Sciences 8, 227-234.

Muruganandam, L., Saravana Kumar, M., Jena, A., Gulla, S., Godhwani, B., 2017. Treatment of waste water by coagulation and flocculation using biomaterials, Materials Science and Engineering Conference Series, pp. 032006.

Nakhate, P.H., Moradiya, K.K., Patil, H.G., Marathe, K.V., Yadav, G.D., 2020. Case study on sustainability of textile wastewater treatment plant based on lifecycle assessment approach. Journal of Cleaner Production 245, 118929.

Nkalane, A., Oyewo, O., Leswifi, T., Onyango, M.S., 2019. Application of coagulant obtained through charge reversal of sawdust-derived cellulose nanocrystals in the enhancement of water turbidity removal. Materials Research Express 6. 105060.

Omoike, A., 1999. Removal of phosphorus and organic matter removal by alum during wastewater treatment. Water Research 33, 3617-3627.

Owamah, H.I., Chukwujindu, I.S., Asiagwu, A.K., 2013. Biosorptive capacity of yam peels waste for the removal of dye from aqueous solutions. Civil and Environmental Research 3, 36-34.

Pathiraja, I.K., 2014. Removal of acid yellow 25 dye onto chitin extracted from waste crab legs and study of adsorption isotherms and kinetics of AY25 dye adsorption. Southern Illinois University at Edwardsville.

Pensini, E., Dinardo, A., Lamont, K., Longstaffe, J.G., Elsayed, A., Singh, A., 2019. Effect of salts and $\mathrm{pH}$ on the removal of perfluorooctanoic acid (PFOA) from aqueous solutions 
through precipitation and electroflocculation. Canadian Journal of Civil Engineering 10, 881-886.

Prakash, N., Sockan, V., Jayakaran, P., 2014. Waste water treatment by coagulation and flocculation. International Journal of Engineering Science and Innovative Technology $3,479-484$.

Premarathne, H., Udagedara, T., Young, S., 2019. Assessment of phytoremediation to treat selected metals in textile wastewater. 192.248.93.15/handle/123456789/219

Rafatullah, M., Sulaiman, O., Hashim, R., Ahmad, A., 2010. Adsorption of methylene blue on low-cost adsorbents: a review. Journal of Hazardous Materials 177, 70-80.

Restiani, P., 2016. Water governance mapping report: textile industry water use in Bangladesh. Sweden Textile Water Initiative, pp. 1-49.

Semmens, M.J., Field, T.K., 1980. Coagulation: experiences in organics removal. Journal-American Water Works Association 72, 476-483.

Shertate, R., Thorat, P., 2013. Biotransformation of a textile azo dye acid yellow 25 by Marinobacter gudaonensis AY-13. Journal of Engineering and Applied Sciences 2, 35-45.

Shishaye, H., Abdi, S., 2016. Groundwater exploration for water well site locations using geophysical survey methods. Hydrology: Current Research 7, 2.

Singh, M.R., Gupta, A., 2016. Water pollution-sources, effects and control. Pointer Publishers Jaipur.

Sun, H., Jiao, R., Xu, H., An, G., Wang, D., 2019. The influence of particle size and concentration combined with $\mathrm{pH}$ on coagulation mechanisms. Journal of Environmental Sciences 82, 39-46.

Verma, A.K., Dash, R.R., Bhunia, P., 2012. A review on chemical coagulation/flocculation technologies for removal of colour from textile wastewaters. Journal of Environmental Management 93, 154-168.

Wang, C., Zhao, H., Dai, Z., Li, W., Liu, H., 2019. The effect of inorganic salt in wastewater on the viscosity of coal water slurry. Environmental Science and Pollution Research 26, 14171-14177.

Wang, Y., Chu, W., 2011. Adsorption and removal of a xanthene dye from aqueous solution using two solid wastes as adsorbents. Industrial and Engineering Chemistry Research 50, 8734-8741.

Woisetschläger, D., Humpl, B., Koncar, M., Siebenhofer, M., 2013. Electrochemical oxidation of wastewateropportunities and drawbacks. Water Science and Technology 68, 1173-1179.

Wong, P.W., Teng, T.T., Norulaini, N.A.R.N., 2007. Efficiency of the coagulation-flocculation method for the treatment of dye mixtures containing disperse and reactive dye. Water Quality Research Journal 42, 54-62.

Xu, X., Hou, Q., Xue, Y., Jian, Y., Wang, L., 2018. Pollution characteristics and fate of microfibers in the wastewater from textile dyeing wastewater treatment plant. Water Science and Technology 78, 2046-2054.

Zhou, L., Zhou, H., Yang, X., 2019. Preparation and performance of a novel starch-based inorganic/organic composite coagulant for textile wastewater treatment. Separation and Purification Technology 210, 93-99.

Zin, N., Awang, N., Akbar, N., 2018. Application of alum and chickpea (cicer arietinum) in removing color from leachate, IOP Conference Series: Earth and Environmental Science. IOP Publishing, pp. 012036.

Visit us at: http://bosaljournals.com/chemint/ Submissions are accepted at: editorci@bosaljournals.com 